\title{
Cell and Bacteria-Baterial Interactions on the Ti10Mo8Nb Alloy After Surface Modification
}

\author{
João Pedro Aquiles Carobolante ${ }^{a}$, Cristiane Aparecida Pereira ${ }^{b}$, Marcela Ferreira Dias-Netipanyj ${ }^{a}$, \\ Ketul Chandrakant Popat, Ana Paula Rosifini Alves Claro ${ }^{a *}$ \\ ${ }^{a}$ Escola de engenharia, Universidade Estadual Paulista - UNESP, Guaratinguetá, SP, Brasil \\ ${ }^{b}$ Departamento de Biociências e Diagnóstico Bucal, Universidade Estadual Paulista - UNESP, São José \\ dos Campos, SP, Brasil \\ 'School of Biomedical Engineering, Department of Mechanical Engineering, Colorado State University, \\ Fort Collins, CO 80523, USA
}

Received: May 19, 2017; Revised: May 10, 2018; Accepted: May 16, 2018

\begin{abstract}
The purpose of this study is the surface modification of Ti10Mo8 $\mathrm{Nb}$ experimental alloy by using $\mathrm{TiO}_{2}$ nanostructure growth. Ingots of the $\mathrm{Ti} 10 \mathrm{Mo} 8 \mathrm{Nb}$ experimental alloy were produced by fusion from sheets of molybdenum, niobium, and titanium commercially pure in an arc melting furnace under argon atmosphere. The potentiostatic anodic oxidation was performed using an electrolyte formed of glycerol and $\mathrm{H}_{2} \mathrm{O}$ (1: 1 by vol.) with the addition of $2.7 \%(\mathrm{w} / \mathrm{v}) \mathrm{NH}_{4} \mathrm{~F}$ under $20 \mathrm{~V}$ for $3 \mathrm{~h}$ at room temperature. After the surface treatment, the samples were annealing. The surface of the alloy was analyzed by scanning electron microscopy (SEM), X-ray diffraction (XRD), contact angle, surface energy measurements. In vitro studies, such as cell and bacterial adhesion, were performed to evaluate the response of this treatment. The Ti10Mo8 $\mathrm{Nb}$ alloy exhibited beta phase after the processing. After the surface treatment, a nanoporous layer of TiO was obtained. The anatase phase was found in the annealed samples $\left(450^{\circ} \mathrm{C}\right.$ for 3 hours). In vitro analyzes showed cell growth viability and decreased bacterial proliferation due to the larger specific surface area.
\end{abstract}

Keywords: Titanium alloys, surface modification, cell-material interactions, bacterial adherence.

\section{Introduction}

Biometallic materials (stainless Steel, cobalt-chromium and titanium alloys) have been extensively studied for replacing hard tissues due to excellent bulk properties.

Among titanium alloys, Ti10Mo8Nb alloy has been evaluated for biomedical applications due to excellent mechanical properties. Studies with Ti-Mo-Nb alloys with the composition near the Ti10Mo8Nb alloy exhibited the low modulus of elasticity (less than $30 \mathrm{GPa}$ ) and high hardness (394 to $444 \mathrm{GPa}$ ) when compared to commercially pure titanium ${ }^{1}$. Also, It has been reported to have good corrosion resistance due to the addition of niobium to Ti-Mo alloy ${ }^{2}$. This alloy exhibited no cytotoxic effects on MC3T3-E1 preosteoblasts cells and no significant inflammatory response ${ }^{3}$.

However, besides these properties, the success of metallic implants after insertion into the human body is to related to surface properties, such as surface energy, chemical composition, and topography. Surface modification techniques could be a viable alternative to obtaining desired properties.

Anodizing is an excellent alternative for surface modification, creating nanostructures from the $\mathrm{TiO}_{2}$ layer that is formed spontaneously on titanium and its alloys ${ }^{4}$. These nanostructures leading to cell growth due to better wettability and roughness for anchoring cells and pruning bacterial adhesion due to the higher surface area ${ }^{5,6}$.
To our knowledge, no previous studies have been performed to assess the influence of surface modification of Ti10Mo8 $\mathrm{Nb}$ on cell and bacteria response. The purpose of this study was to evaluate the effect of the nanoporous topography on the Ti10Mo8 $\mathrm{Nb}$ alloy surface on cell and bacteria adhesion compared to a compact layer.

\section{Materials and Methods}

\subsection{Ti10Mo8Nb alloy processing}

The Ti10Mo8 $\mathrm{Nb}$ alloy was obtained from the melting of titanium (grade 2), molybdenum $(99,99 \%)$ and niobium $(99,9 \%)$ in an arc furnace under an inert atmosphere of argon gas. The ingot was melted at least 10 times to ensure chemical homogeneity. The alloy was homogenized in vacuum at $1000{ }^{\circ} \mathrm{C}$ for $24 \mathrm{~h}$ and solubilized at $950{ }^{\circ} \mathrm{C}$ for 1 hour and quenched in water.

After the heat treatment, the ingot was cold-worked by a rotary swaging process until a diameter of $10 \mathrm{~mm}$. Then the bar was solubilized at $950^{\circ} \mathrm{C}$ for 1 hour and quenched in water.

The ingots were sectioned in discs with a thickness of 3 $\mathrm{mm}$, polished in sandpaper with 1200 mesh and cleaned in an ultrasonic bath with water and soap (20 min), deionized water (20 $\mathrm{min})$ and isopropyl alcohol (5 $\mathrm{min})$. 


\subsection{Anodization of Ti10Mo8Nb alloy}

The samples were anodized for $3 \mathrm{~h}$ with a potential of $20 \mathrm{~V}(200 \mathrm{mV} / \mathrm{s})$. The electrolyte was composed of glycerol and deionized water $(1: 1)$ with added $0,27 \%(\mathrm{~m} / \mathrm{v})$ of NH4F. After treatment, the discs were washed in an ultrasonic bath with deionized water for $5 \mathrm{~s}$. Then the samples were annealed at $450^{\circ} \mathrm{C}$ for $1 \mathrm{~h}$.

The topography after anodization of the samples was evaluated by SEM (FEI Magellan 400 L). The microstructure of the nanoporous layer and polished surfaces (control group) was evaluated by XRD (Panalytical X'Pert) using $\mathrm{CuK} \alpha$ radiation, the current of $40 \mathrm{~mA}$, the voltage of 45 $\mathrm{kV}$, measuring range $2 \theta$ from $5^{\circ}$ to $90^{\circ}$ and pace of $0,02^{\circ}$.

The wettability was analyzed on the control group and after anodizing. The measurements were performed at room temperature with deionized water in goniometer (Krüss, DAS 100S) using the sessile drop method. The surface energy of the polished and after anodization samples were measured using a goniometer (Ramèttart 300-ft), deionized water, and ethylene glycol. The procedure was performed at room temperature.

\subsection{In vitro studies}

Prior to the cell and bacterial culture, the samples were sterilized by gamma radiation (IPEN). Two groups were analyzed, with the surface polished and after anodizing treatment.

\subsubsection{Bacterial proliferation}

The analysis was performed according to the methodology proposed by Pereira et al. (2010) using standard strains of Staphylococcus epidermidis (ATCC 12228). The strains were seeded in agar brain heart infusion (BHI) (Difco) and incubated at $37^{\circ} \mathrm{C}$ for $24 \mathrm{~h}$. After colonies of microorganisms were suspended in phosphate buffer saline (PBS) (Gibco) and adjusted to a concentration of $10^{6}$ cells $/ \mathrm{mL}$ with the use of a spectrophotometer (AJX-1900, Micronal).

The discs were placed in 24-well plates with $2 \mathrm{~mL}$ of BHI supplemented with $5 \%$ sucrose and inoculated with 0,1 $\mathrm{mL}$ of the bacterial suspension. The samples were incubated at $37^{\circ} \mathrm{C}$ for $48 \mathrm{~h}$, and the media was changed after $24 \mathrm{~h}$.

After that period, the discs were washed aseptically with $2 \mathrm{~mL}$ of PBS and placed in tubes with $10 \mathrm{~mL}$ of PBS and sonicated (30 W, Sonics Vibra Cell) for $30 \mathrm{~s}$ to dispersive the biofilms. The suspension was considered to have a dilution factor of $10^{-1}$ and was diluted with the addition of PBS to $10^{-8}$. Aliquots of $0,1 \mathrm{~mL}$ were seeded on $\mathrm{BHI}$ agar plates and incubated for $48 \mathrm{~h}$ at $37^{\circ} \mathrm{C}$.

The number of colonies was counted, calculated in $\mathrm{CFU} / \mathrm{mL}$ and transformed in $\log 10$. The obtained result was statistically evaluated by the $t$-student test, considering a statistical difference when $\mathrm{p}<0,005$. The sample after proliferation bacteria and control group were evaluated by SEM (Zeiss, EVO MA 10).

\subsubsection{Cell culture}

Stem cells derived from adipose tissue (ADSC) were used to verify cell viability, adhesion, and proliferation after 1 and 7 days of culture.

For viability analysis, adhered cells were incubated for $4 \mathrm{~h}$ at $37{ }^{\circ} \mathrm{C}$ in fresh $\alpha$-MEM with $10 \%$ Alamar blue reagent. After that period the optical density of the solution at 570 and $600 \mathrm{~nm}$ was measured using a spectrophotometer (FLUO - Star Omega; BMG Labtech).

Adhesion and proliferation cell was analyzed by incubating the samples in Triton - X100 (1\%) for 3 min and then washed in PBS. The cells were incubated in rhodamine phalloidin dye (actin-cytoskeleton) at $70 \mathrm{mM}$ for $30 \mathrm{~min}$ at room temperature and in the final $5 \mathrm{~min}, 4^{\prime} 6$ - diamidino 2 - phenylindole DAPI at $300 \mathrm{mM}$ was added. After which, the entire solution was aspirated, and surfaces were washed with PBS.

The number of the cells adhered and their dispersion was analyzed with a fluorescence microscope and the image J software. The adhesion cellular after 1 and 7 days was evaluated by SEM (FEI Magellan 400 L).

\section{Results and Discussion}

In figure 1 is possible to observe the top morphology and cross-section of the samples: (a) alloy (grounded), (b) after anodizing and cross section after anodizing. The surface anodization of the Ti10Mo8Nb alloy resulted in a nanoporous $\mathrm{TiO}_{2}$ layer with an internal diameter of $23 \mathrm{~nm}$ and a length of $200 \mathrm{~nm}$.

The substrate showed peaks indexed to the $\beta$ phase resulting from heat treatments and alloy composition (Figure 2). The nanoporous layer is grown on the surface of the Ti10Mo8 $\mathrm{Nb}$ alloy no presented new peaks in relation to the substrate. After annealing at $450{ }^{\circ} \mathrm{C}$, the peaks were indexed to the anatase phase, which according to studies is a structure more favorable to cell growth, due to the higher number of filopodia and reduction of bacteria adhesion ${ }^{5,7}$. The substrate structure is not affected by the heat treatment, with the same peaks previously observed.

The wettability of the Ti10Mo8Nb alloy surface changed after the surface modification. The results showed the reduction of the contact angle from $72^{\circ}$ to $12^{\circ}$ (Table 1), values confirmed by surface energy measurements, which was approximately double after treatment. The hydrophilicity of the material induces better contact with the body fluids, which results in a better cellular development ${ }^{8}$.

The Ti10Mo8Nb alloy presented viable growth, coating and cell proliferation on the surface during the analyzed period. There was improve mitochondrial cell activity, observed by reduction of the Alamar blue reagent, but there was a statistical difference between the control and anodized groups (Figure 3). 


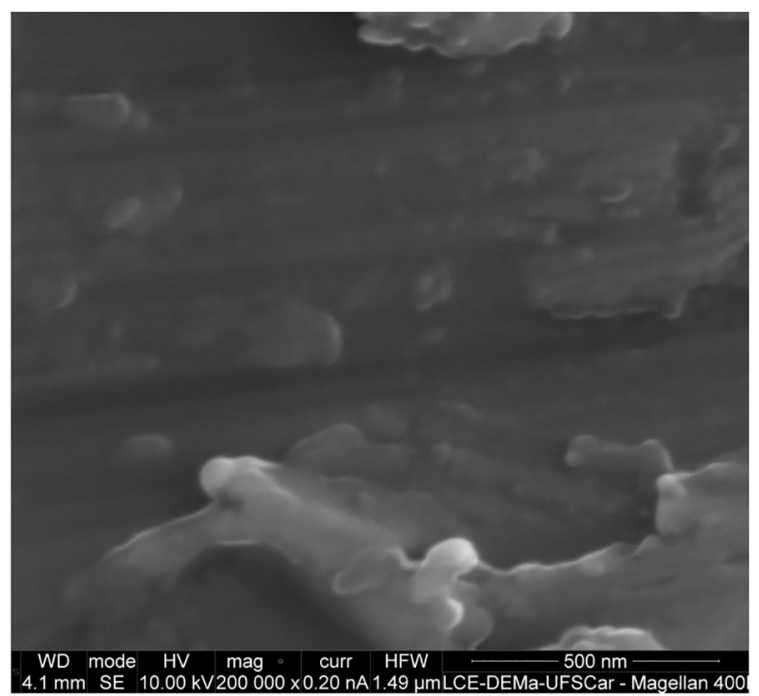

(a)

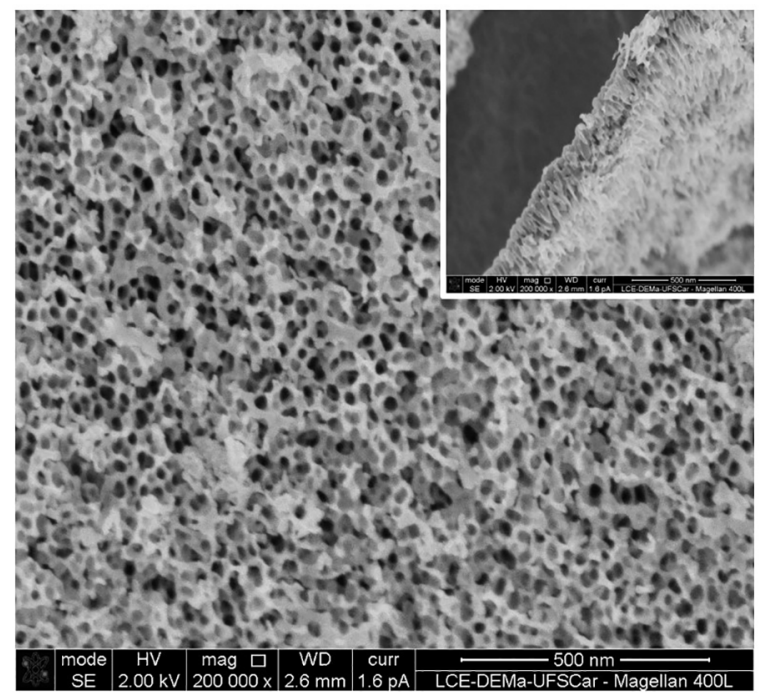

(b)

Figure 1. SEM imagens of the bottow views of (a) Ti10Mo8 $\mathrm{Nb}$ alloy (b) nanoporous layer on the Ti10Mo8 $\mathrm{Nb}$

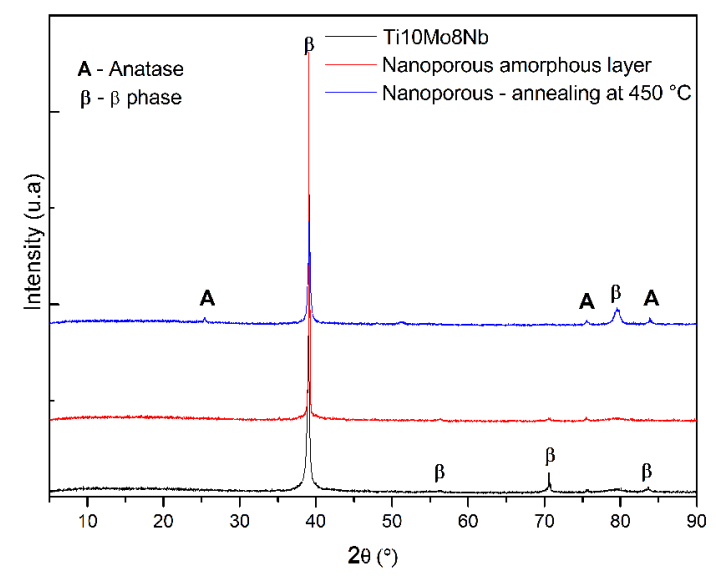

Figure 2. X-ray diffraction (XRD) analysis of Ti10Mo8 $\mathrm{Nb}$ alloy and after surface modification (nanoporous layer)

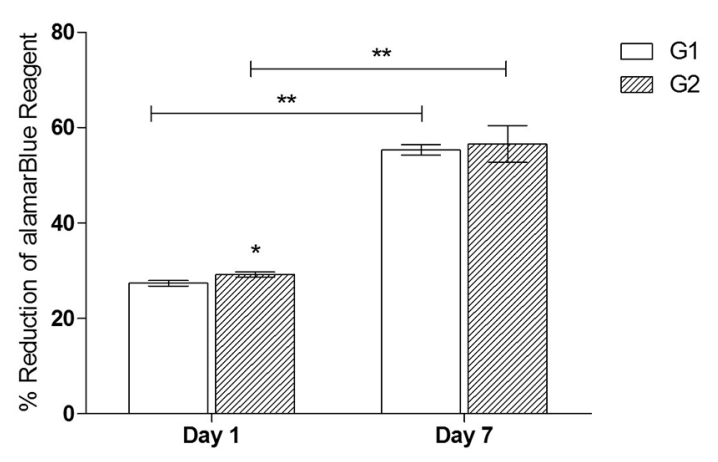

Figure 3. Cell viability after 1 and 7 days of cell culture represented as percentage reduction of alamar Blue reagent. Results are presented as mean $\pm \mathrm{SD}(\mathrm{n}=5) .(* * *) \mathrm{p}<0,001$ using one-way ANOVA test and Tukey HDS to multiple comparisons, SPSS 13.0 software.

Table 1. The aqueous contact angle for the Ti10Mo8 $\mathrm{Nb}$ alloy and Ti10Mo8Nb after TiO2 nanotubes growth

\begin{tabular}{lll}
\hline Sample & Contact angle $\left({ }^{\circ}\right)$ & Surface energy $\left(\mathrm{mJ} / \mathrm{m}^{2}\right)$ \\
\hline Substrate & $72,03 \pm 9,31$ & $36,94 \pm 1,5$ \\
Nanoporous layer & & \\
6
\end{tabular}


In figure 4 it was possible to observe by fluorescence microscopy images cell proliferation was evaluated after Day 1 and Day 7 of culture. The cell count adhered to the surface indicates that both the control and nanoporous groups are viable to cell growth. There was an increase in the number of cells in both cases when compared to days 1 and 7 .

The nanoporous surface showed a better result on day 1. When comparing the seventh day, a larger number of cells were counted under the polished surface, but when performing the Mann-Whitney statistical test, no significant difference was observed between the groups, only between the days (Figure 5 (a)).

The same was observed for the coverage (Figure 5 (b)), there was an increase in the surface covered by the cells between the evaluated days, but without significant difference between the groups. The elongated format leads to a greater coverage which does not imply a greater adhesion due to overlap.

The evaluation of bacterial adhesion (S. epidermidis) resulted in a significant difference in the number of colonies forming units (Figure 6). The nanoporous layer presented better results, although the groups presented close values.

Li et al (2013) found that in surfaces with a higher specific surface area, with smaller pore diameters, there is a trend of lower bacterial adhesion. In this study, the pores had a diameter around $20 \mathrm{~nm}$, which should have influenced the best result for the treated surface.

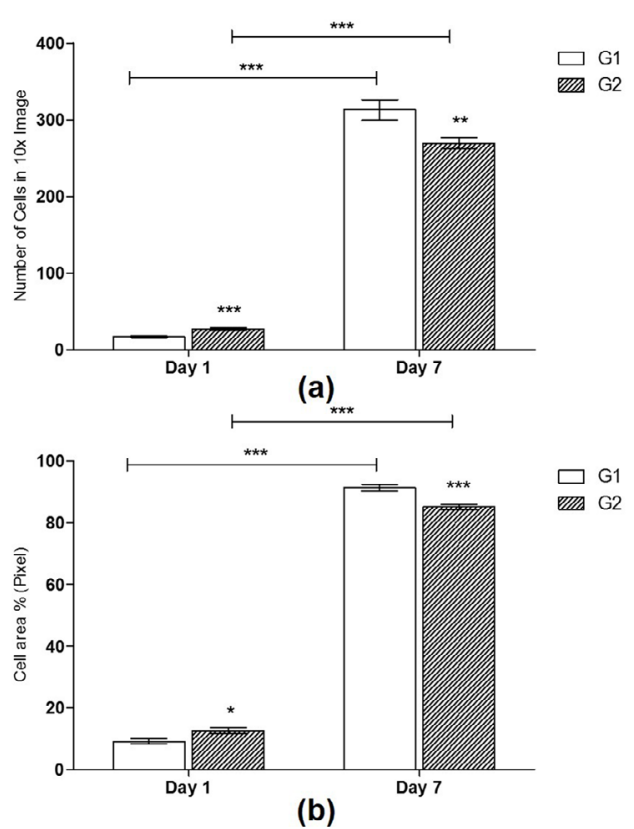

Figure 5. (a) Number of cells on surfaces after 1 and 7 days of culture. Cell nuclei were counted using DAPI fluorescence. Result are presented as mean \pm SD. $\left({ }^{* *}\right) \mathrm{p}<0,001$ using one-way ANOVA test and Tukey HDS to multiple comparisons, SPSS 13.0 software. (b) Area of cell coverage after land 7 days of culture. Cell cytoskeleton (Actin filaments) was quantified using rhodamine-phalloidin fluorescence. Result are presented as mean \pm SD . $(* *) p<0,01,(* * *) p<0,001$ using one-way ANOVA test and Tukey HDS to multiple comparisons, SPSS 13.0 software
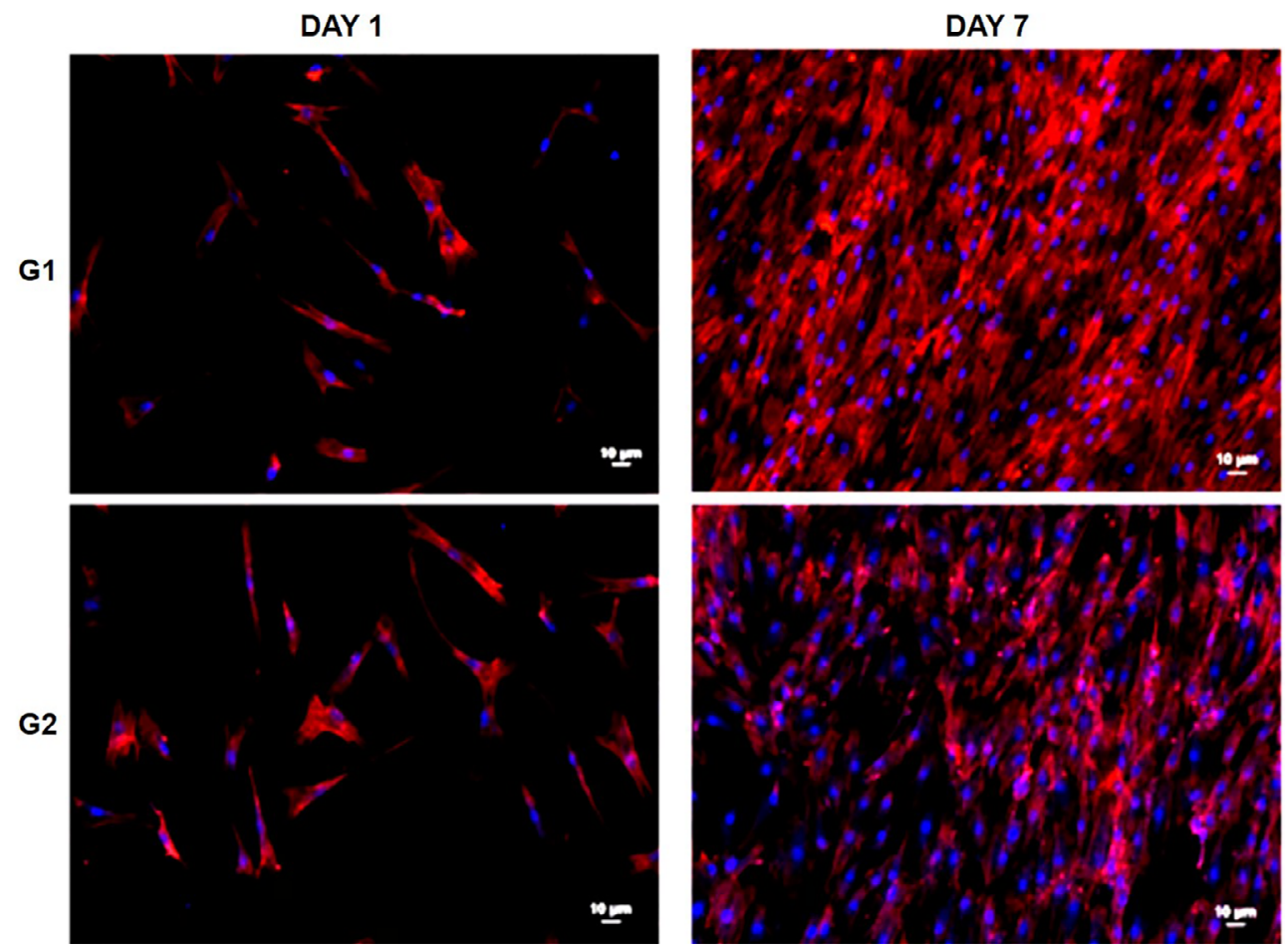

Figure 4. Morphology of human adipose cells over samples of Ti10Mo8Nb (a) no treated and (b) after anodization at room temperature, with a constant potential of $20 \mathrm{~V}$ for $3 \mathrm{~h}$ in an electrolyte containing glycerol in combination with ammonium fluoride (NH4F) and annealing at $450{ }^{\circ} \mathrm{C}$ 


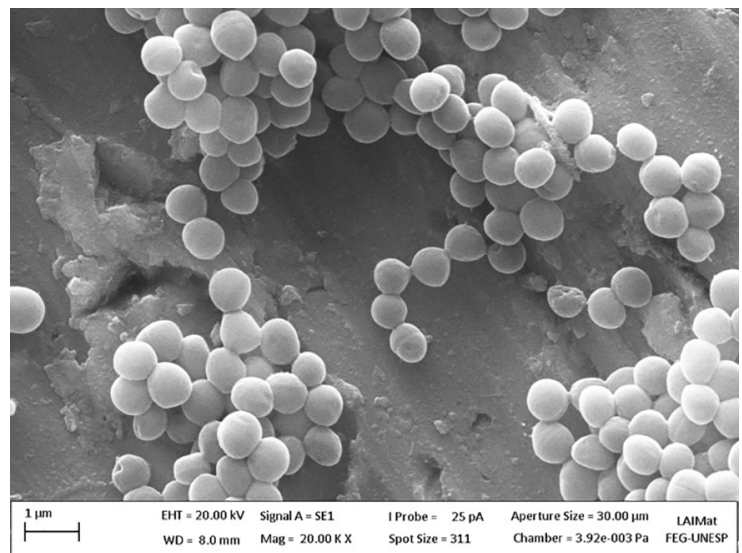

(a)

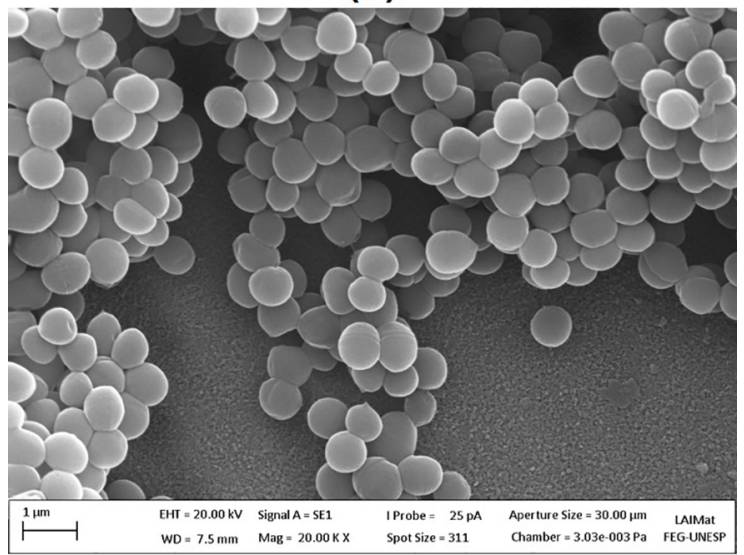

(b)

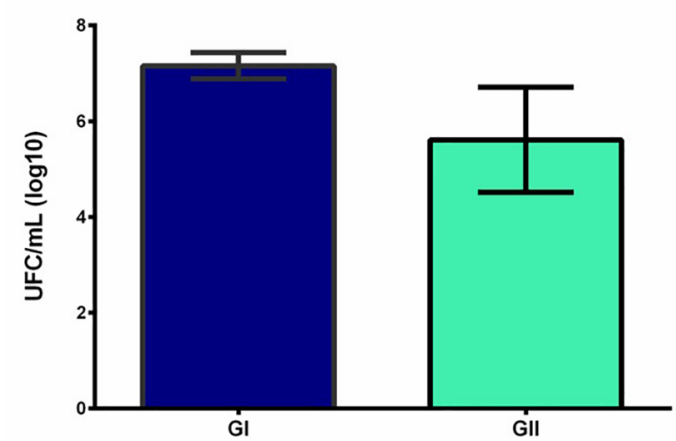

(c)

Figure 6. Bacteria proliferation on the Ti10Mo8 $\mathrm{Nb}$ alloy (a) oxide layer, (b) nanoporous layer and (c) statistical analysis

\section{Conclusions}

The anodizing treatment resulted in a nanoporous layer with large surface area due to small pore diameters.
Annealing of the treated samples resulted in an anatase structure of the nanoporous

The cell culture showed a growth of cellular activity, with proliferation and greater surface coverage. Although there is no significant difference between the treated layer and the control group, the Ti10Mo8Nb alloy with a growth of a nanoporous layer becomes an option for biomedical applications, since it presented anti-biofouling surface.

\section{Acknowledgments}

This research was supported by CNPq Conselho Nacional de Desenvolvimento Científico e Tecnológico (Grant 486352/2013-7).

\section{References}

1. Xu LJ, Chen YY, Liu ZG, Kong FT. The microstructure and properties of $\mathrm{Ti}-\mathrm{Mo}-\mathrm{Nb}$ alloys for biomedical application. Journal of Alloys and Compounds. 2008;453(1-2):320-324.

2. Chelariu R, Bolat G, Izquierdo J, Mareci D, Gordin DM, Gloriant T, et al. Metastable beta Ti-Nb-Mo alloys with improved corrosion resistance in saline solution. Electrochimica Acta. 2014;137:280-289.

3. Neacsu P, Gordin DM, Mitran V, Gloriant T, Costache M, Cimpean A. In vitro performance assessment of new beta TiMo-Nb alloy compositions. Materials Science and Engineering: C. 2015;47:105-113.

4. Regonini D, Bowen CR, Jaroenworaluck A, Stevens R. A review of growth mechanism, structure and crystallinity of anodized $\mathrm{TiO}_{2}$ nanotubes. Materials Science and Engineering. R: Reports. 2013;74(12):377-406.

5. Bai Y, Park IS, Park HH, Lee MH, Bae TS, Duncan W, et al. The effect of annealing temperatures on surface properties, hydroxyapatite growth and cell behaviors of $\mathrm{TiO}_{2}$ nanotubes. Surface and Interface Analysis. 2011;43(6):998-1005.

6. Pereira CA, Romeiro RL, Costa ACBP, Machado AKS, Junqueira JC, Jorge AOC. Susceptibility of Candida albicans, Staphylococcus aureus, and Streptococcus mutans biofilms to photodynamic inactivation: an in vitro study. Lasers in Medical Science. 2011;26(3):341-348.

7. Li H, Cui Q, Feng B, Wang J, Lu X, Weng J. Antibacterial activity of $\mathrm{TiO}_{2}$ nanotubes: influence of crystal phase, morphology and Ag deposition. Applied Surface Science. $2013 ; 284: 179-183$

8. Rupp F, Scheideler L, Olshanska N, de Wild M, Wieland M, Geis-Gerstorfer J. Enhancing surface free energy and hydrophilicity through chemical modification of microstructured titanium implant surfaces. Journal of Biomedical Materials Research. 2006;76A(2):323-334. 